13

\title{
Анизотропия поверхностной энергии и работы выхода электрона IIB металлов
}

\author{
(С) И.Г. Шебзухова, ${ }^{1}$ Л.П. Арефьева ${ }^{2, \uparrow}$ \\ ${ }^{1}$ Кабардино-Балкарский государственный университет им. Х.М. Бербекова, \\ 360004 Нальчик, Россия \\ 2 Донской государственный технический университет, \\ 344000 Ростов-на-Дону, Россия \\ ฯ e-mail: Ludmiloch ka529@mail.ru, Irina.Shebzukhova@mail.ru
}

(Поступило в Редакцию 13 мая 2018 г. В окончательной редакции 18 июня 2018 г.)

\begin{abstract}
На базе электронно-статистического метода расчета поверхностной энергии металлов разработана методика оценки работы выхода электрона металлических кристаллов с гексагональными и ромбоэдрическими структурами. Предлагаемая методика связывает величину поверхностной энергии граней с работой выхода электрона, что позволяет также применять ее для оценки поверхностной энергии граней по экспериментальным данным работы выхода. Расчеты проводились для макрокристаллов кадмия, цинка и ртути. Построены температурная и ориентационная зависимости обеих величин. Полученные нами результаты хорошо согласуются с известными литературными данными.
\end{abstract}

DOI: $10.21883 / J T F .2019 .02 .47087 .188-18$

\section{Введение}

Анизотропия поверхностной энергии (ПЭ) и работы выхода электрона (РВЭ) металлических кристаллов и пленок является одним из основных факторов, который необходимо учитывать при решении практических задач техники и технологии. Поэтому на протяжении нескольких десятилетий данному вопросу уделяется большое внимание [1-13]. Экспериментальные данные по ПЭ металлов и ее ориентационной зависимости неоднозначны или даже отсутствуют в справочной литературе [14]. В то же время РВЭ с ориентированной поверхности относительно несложно измерить. Современные экспериментальные методики определения РВЭ, основанные на применении метода сканирующего зонда Кельвина, используются при диагностике состояния поверхности, подвергающейся деформациям разного рода [10-13]. В справочной литературе [14] имеются экспериментальные данные РВЭ для большинства металлических поликристаллов, а также для некоторых металлов хотя бы для одной грани кристалла, а для некоторых $d$-металлов - для трех и более кристаллических граней.

Разными авторами экспериментально и теоретически $[1,2,4-9]$ изучалась связь между РВЭ и ПЭ. В пионерской работе Г.Н. Шуппе [1] были установлены соотношения между величинами РВЭ, ПЭ и плотностью упаковки кристаллических граней.

Целью настоящей работы являлось распространение электронно-статистического метода расчета ПЭ металлов на описание связи ориентационных зависимостей работы выхода электрона $\varphi(h k l)$ и поверхностной энергии $f_{\omega}(h k l)$ плотноупакованных граней металлических макрокристаллов с некубическими структурами.

\section{Электронно-статистический подход к расчету работы выхода электрона}

Выражение, связывающее РВЭ и ПЭ металлических кристаллов, было получено в работах [7-9] в рамках электронно-статистической теории. Оно дает хорошее согласие с экспериментальными данными для $d$-металлов с ОЦК- и ГЦК-решетками. В настоящей работе мы применяем его для оценки анизотропии РВЭ гексагональных и ромбоэдрических структур IIB металлов, учитывая температурные зависимости величин, входящих в него.

Формула, связывающая $\varphi(h k l)$ с $f_{\omega}(h k l)$ [7-9], имеет вид

$$
\varphi(h k l)=-\left(\frac{\partial E_{0}}{\partial z}\right)_{\bar{R}}-\frac{1}{n_{v} \tau}\left(\frac{\partial f_{\omega}(h k l)}{\partial z}\right)_{\bar{R}} .
$$

Здесь первое слагаемое есть некоторая постоянная величина, не зависящая от индексов кристаллографических граней, второе определяет ориентационную зависимость РВЭ. Производную $\left(\frac{\partial f_{\omega}(h k l)}{\partial z}\right)_{\bar{R}}$ можно получить по формуле, полученной ранее для ПЭ граней металлических кристаллов на основе электронно-статистического метода, используя выражения для хода электронной плотности на границе металл вакуум по Томасу-Ферми с поправками [15]

$$
f_{\omega}(h k l) \cong \frac{1}{5} n(h k l)\left|W\left(r_{0}\right)\right| Q .
$$

В формулах (1) и (2) $a$ - параметр кристаллической решетки, $z$ - число свободных электронов на атом, $Q$ - функция, слабо зависящая от $z,\left|W\left(r_{0}\right)\right|-$ энергия связи кристаллической решетки, $n(h k l)$ - концентрация частиц на грани. Суммирование в (2) для каждой грани 
проводилось до $j$-й плоскости, при которой вклад в ПЭ составлял $\leq 0.1 \mathrm{~mJ} / \mathrm{m}^{2}$.

При эффективной толщине моноатомного поверхностного слоя $\tau=\bar{R}$ (где $\bar{R}$ радиус $s$-сферы) и имея в виду (2), получим

$$
\varphi(h k l)+\frac{B}{z} a^{2} f_{\omega}(h k l)=\text { const. }
$$

Постоянная $B$ зависит от типа структуры решетки металла и в первом приближении для ГПУ кристаллов равна 3.51 , а для кристаллической ртути с ромбоэдрической решеткой 5.846 .

Мы уточнили константу $B$, для чего провели дифференцирование выражения для ПЭ граней по $z$, учли в производной и второе слагаемое, которое отражает ориентационную зависимость $B$, тогда для металлических кристаллов постоянную $B$ можно записать в виде

$$
B=\frac{a \beta}{R f_{v}}\left[2-\left(1+\frac{\delta(h k l)}{2 b \lambda s}\right)^{-1} \frac{\delta}{2 b \lambda s}\right] .
$$

Здесь для ромбоэдрической структуры численный коэффициент $\beta=\sqrt{1-3 \cos ^{2} \alpha+2 \cos ^{3} \alpha}\left(\alpha=70.74^{\circ}\right)$, для ГПУ $\beta=0.86 c / a, f_{v}$ - плотность упаковки ячейки.

Выражение (3) хорошо передает анизотропию $\varphi(h k l)$ металлов. Для оценки анизотропии РВЭ формула (3) приводится к виду:

$$
\varphi(h k l)=\varphi_{0}\left(1-\frac{f_{\omega}^{T}(h k l)}{f_{0}}\right) .
$$

Здесь $\varphi_{0}=\mathrm{const}=\bar{\varphi}+\frac{B}{z} a^{2} \bar{f}_{\omega}, f_{0}=\varphi_{0} z / B a^{2}, \bar{\varphi}-$ ричардсоновская РВЭ из поликристаллического образца, $\bar{f}_{\omega}$ - поверхностное натяжение (ПН) жидкого металла при температуре плавления $T_{m}, f_{\omega}^{T}(h k l)-$ ПЭ граней при заданной температуре.

При количественной проверке (3) было использовано выражение для разности РВЭ различных граней кристалла

$$
\Delta \varphi=-B a^{2} \Delta f_{\omega} / z,
$$

где $\Delta \varphi$ и $\Delta f_{\omega}-$ соответственно разности РВЭ и свободной ПЭ двух различных граней. Это соотношение сравнивается с экспериментальными данными $\Delta \varphi_{\text {exp. }}$

Для оценки РВЭ поликристалла применили формулу

$$
\bar{\varphi}_{\text {theor }}=\frac{\sum_{i=1}^{n} g_{i} \varphi_{i}}{\sum_{i=1}^{n} g_{i}}
$$

где $g_{i}$ - статистический вес $i$-й грани, $\varphi_{i}=\equiv \varphi(h k l)$.

\section{Обсуждение результатов}

По выражениям (2) и (5) проведены оценки ПЭ и РВЭ четырех основных граней кристаллов кадмия и цинка и пяти граней ртути. Зависимость значений $f_{\omega}^{T}(h k l)$
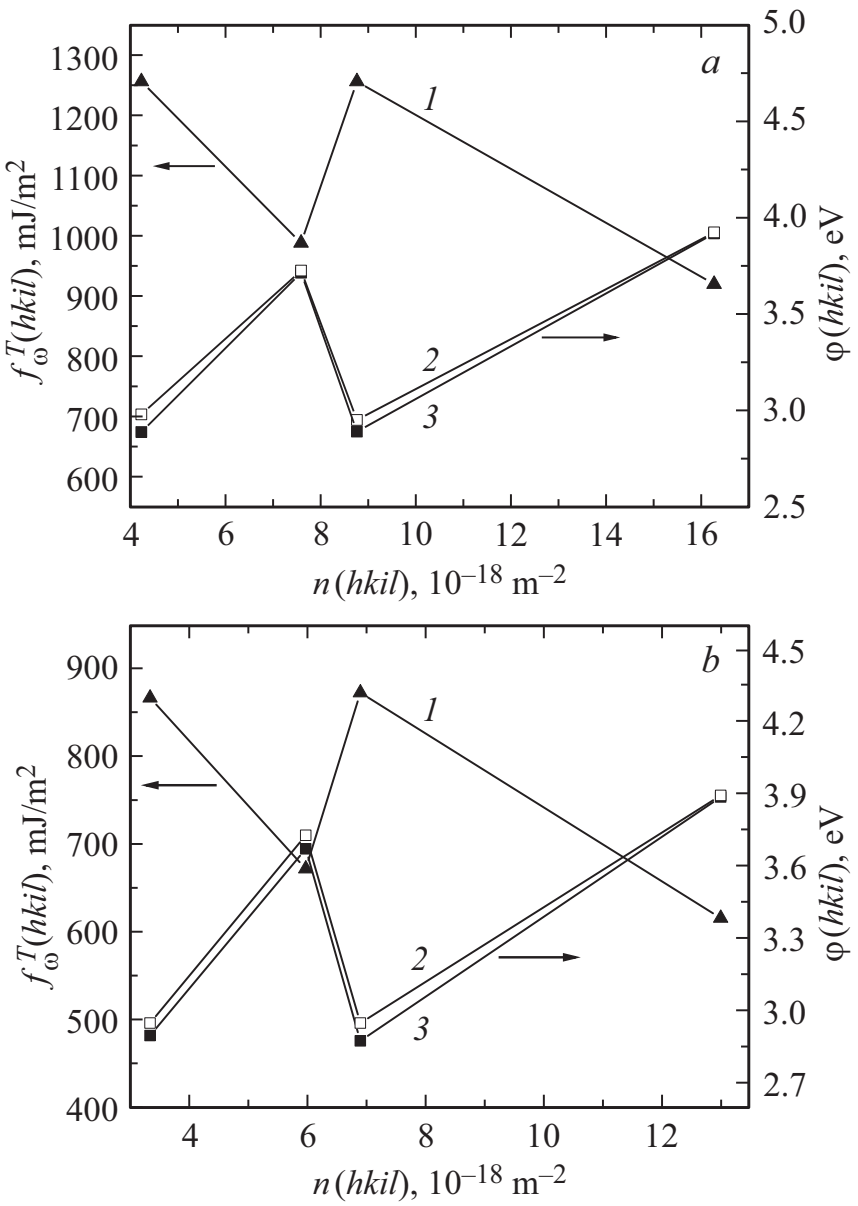

Рис. 1. Зависимость РВЭ и ПЭ граней макрокристаллов цинка $(a)$ и кадмия $(b)$ от концентрации частиц на гранях при $293 \mathrm{~K}: 1-f_{\omega}^{T}(h k i l) ; 2-\varphi(h k i l)$ с учетом $(3) ; 3-$ для $\varphi(h k i l)$ для $B=3.51$.

и $\varphi(h k l)$ от плотности упаковки граней показана на рис. 1. Как видно из графиков, плотноупакованные грани обладают наименьшей ПЭ и наибольшей РВЭ, что согласуется с известными экспериментальными данными.

Полученные нами величины РВЭ для базисной грани (0001) кадмия и цинка хорошо согласуются с известными экспериментальными данными. Так, для цинка отклонение расчетного значения $\varphi(0001)$ при $293 \mathrm{~K}$ от $\varphi^{\exp }(0001)$ и от значения для поликристалла составляет 7.94 и 7.59\% соответственно. А для кадмия погрешность расчета по сравнению с РВЭ поликристалла составляет всего 5.3\%.

Значения коэффициента $B$, рассчитанные по (4), зависят не только от типа структуры, но и от кристаллографической ориентации грани, что позволяет более адекватно оценить анизотропию РВЭ. Так, для цинка отношения РВЭ граней $(1 \overline{1} 20)$ и $(11 \overline{2} 1)$ к РВЭ базисной грани (0001) уменьшается на $1.5-2 \%$.

На рис. 2 показаны графики зависимости ПЭ и РВЭ пяти граней кристалла ртути от плотности упаковки граней. Расчеты проводились для температуры кристал- 


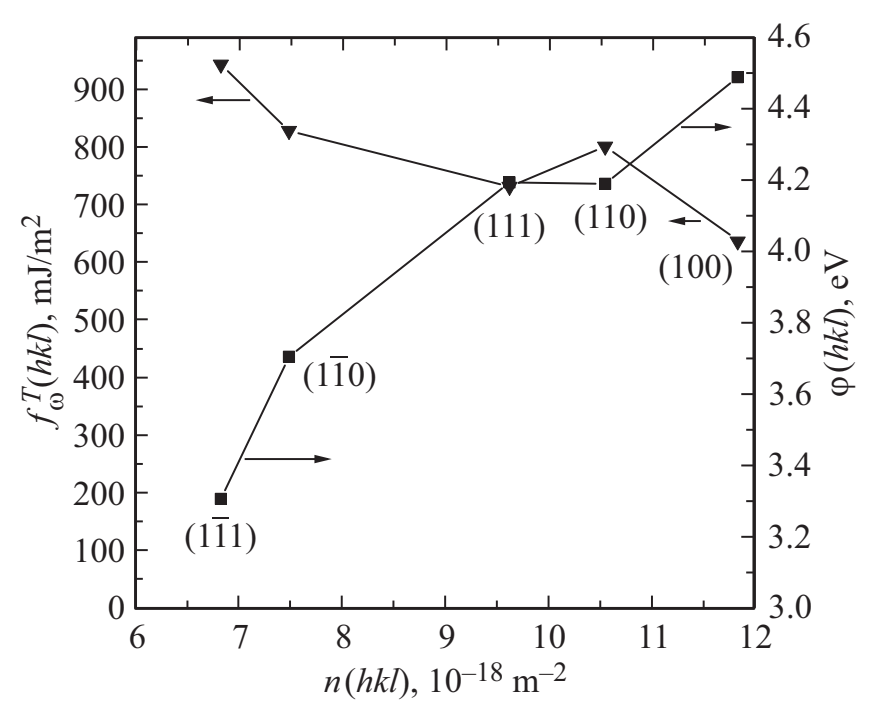

Рис. 2. Зависимость РВЭ и ПЭ граней макрокристалла ртути от концентрации частиц на гранях.

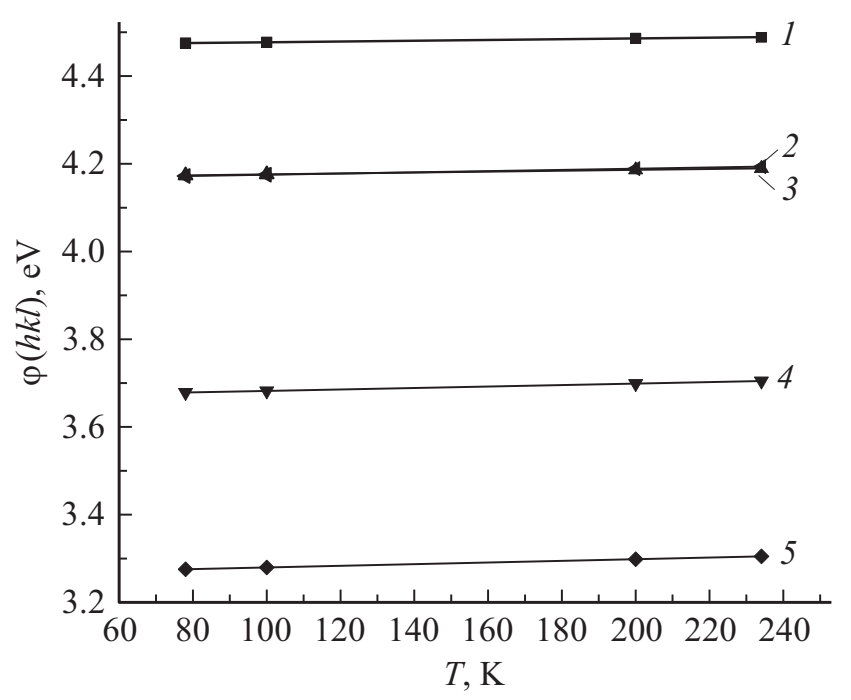

Рис. 3. Температурная зависимость РВЭ граней макрокристалла ртути.

лизации ртути $(234.11 \mathrm{~K})$, а также экстраполировались на температуру $297 \mathrm{~K}$, для которой в литературе [16] имеются достоверные данные ПН. Видно, что, как и для кубических [7-9], для ГПУ-структуры и кристаллов с низкосимметричной ромбоэдрической решеткой ПЭ наиболее плотноупакованных граней минимальна (грани (001) и (100) соответственно), а РВЭ, наоборот, максимальна.

Также получена зависимость РВЭ и ПЭ граней кристаллов ртути, цинка и кадмия от температуры (рис. 3,4). Температурный коэффициент ПЭ отрицателен и имеет величину порядка $10^{-2} \mathrm{~mJ} /\left(\mathrm{m}^{2} \mathrm{~K}\right)$. При увеличении температуры в интервале от 78 до $234.11 \mathrm{~K}$ РВЭ граней макрокристалла ртути незначительно повы- шается. Температурный коэффициент РВЭ для рассматриваемых металлов положителен.

Работа выхода электрона для ртути по данным, приведенным в [14], составляет $4.52 \mathrm{eV}$. В справочнике не указано, к какому агрегатному состоянию и температурному интервалу относится данное значение. Сравнение наших результатов со справочным значением [14] показывает отклонение 1.3\% для грани (100). Поверхностная энергия грани (100), приведенная к температуре плавления, по сравнению с экспериментальными данными для жидкого состояния $(463.1 \mathrm{mN} / \mathrm{m}$ при 293 К [16]) выше на $25 \%$.

Нами построены полярные диаграммы анизотропии ПЭ (рис. 5) и РВЭ (рис. 6) граней кристаллов цинка и кадмия. Как видно из рис. 5 и 6, соотношения величин РВЭ граней выглядят следующим образом $\varphi(11 \overline{2} 1)<\varphi(11 \overline{2} 0)<\varphi(10 \overline{1} 0)<\varphi(0001)$, что также со-

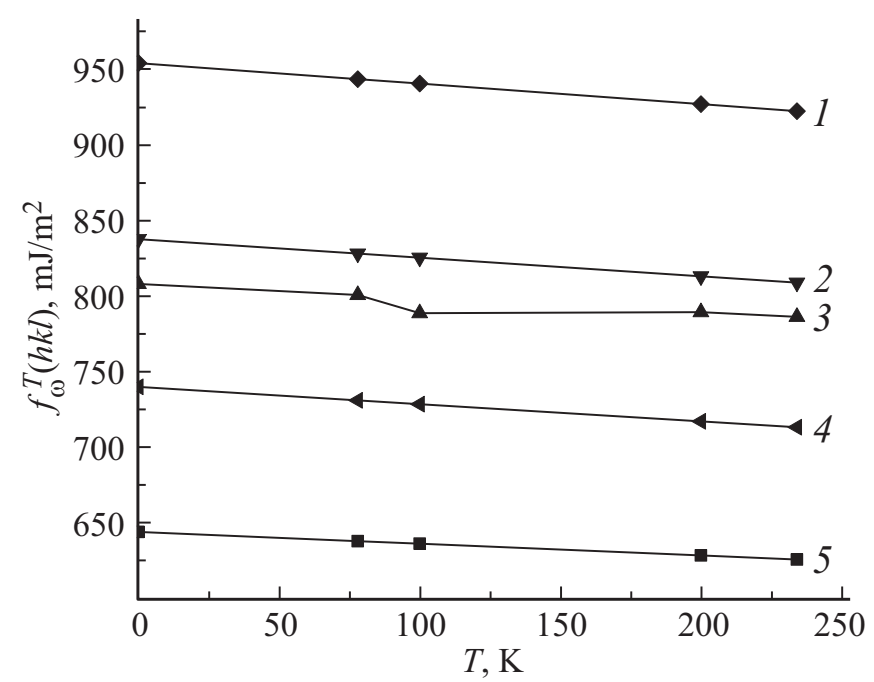

Рис. 4. Температурная зависимость ПЭ граней макрокристалла ртути.

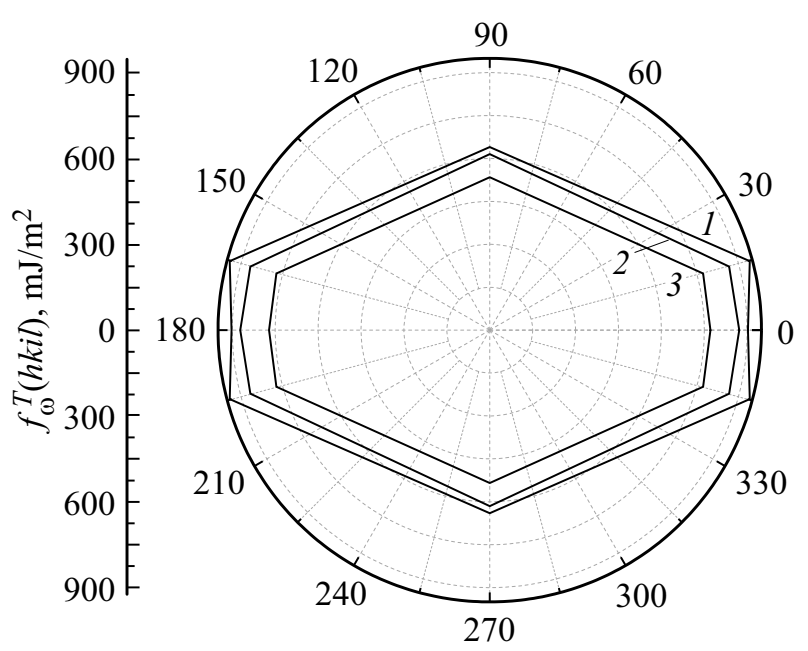

Рис. 5. Полярная $\varphi$-диаграмма для $[\overline{1} 100]$ зоны плоскостей: 1 - ПЭ граней кадмия при $0 \mathrm{~K}, 2-$ ПЭ граней кадмия при $293 \mathrm{~K}, 3$ - ПЭ граней кадмия при $1039 \mathrm{~K}$. 


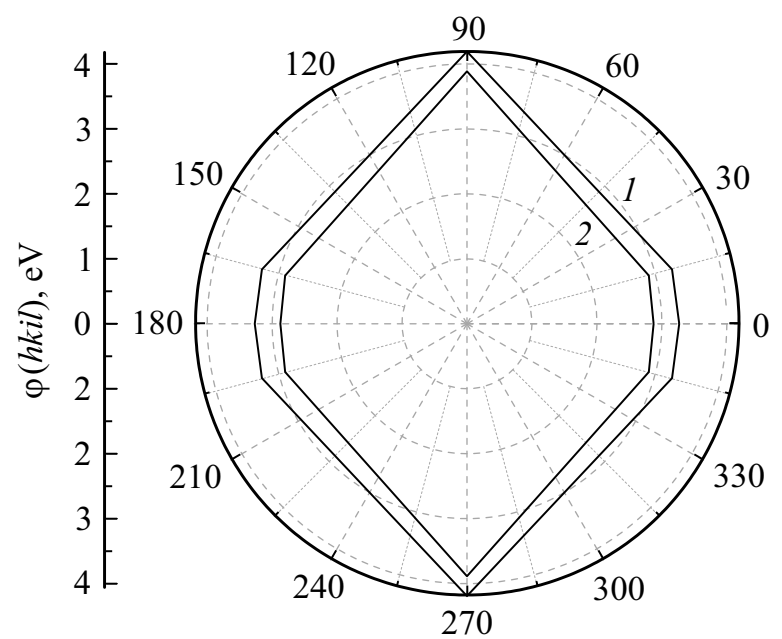

Рис. 6. Полярная $\varphi$-диаграмма для $[\overline{1} 100]$ зоны плоскостей: 1 - РВЭ граней кадмия при $1039 \mathrm{~K}, 2$ - РВЭ граней кадмия при $293 \mathrm{~K}$.

ответствует [1]. Полученные результаты вычислений ПЭ и РВЭ подтверждают резкую анизотропию свойств цинка и кадмия, что характерно для металлов с ГПУ структурой.

\section{Заключение}

Выражения (3) и (5), связывающие РВЭ кристаллов с ПЭ, позволяют корректно оценивать ориентационную зависимость РВЭ макрокристаллов с ГПУ структурами.

Для металла с низкосимметричной кристаллической структурой (ртуть) подобные расчеты проведены впервые и, как показано в настоящей работе, выражения (2) и (3), полученные в рамках модифицированного электронно-статистического метода, позволяют оценить ПЭ граней кристалла с ромбоэдрической структурой и получить данные об анизотропии РВЭ.

Ввиду отсутствия в большинстве случаев и неоднозначности имеющихся экспериментальных данных ПЭ граней монокристаллов с некубическими структурами, тонких пленок и наночастиц рассмотренных металлов, выражения (3) и (5) могут применяться для оценки величины ПЭ металлических поверхностей на границе с вакуумом по данным РВЭ этих поверхностей.

\section{Список литературы}

[1] Шупnе Г.Н. Электронная эмиссия металлических кристаллов. Ташкент: САГУ, 1959. $234 \mathrm{c.}$

[2] Кашетов А., Горбатый Н.А. // ФТТ. 1969. Т. 11. Вып. 2. C. 493-495.

[3] Мамонова М.В., Прудников В.В. // ФММ. 1998. Т. 86. № 2. C. 33-39. [Mamonova M.V., Prudnikov V.V. // The Physics of Metals and Metallography. 1998. Vol. 86. N 2. P. 129-133.]

[4] Wang J., Wang S.-Q. // Surf. Sci. 2014. Vol. 630. P. 216-224.
[5] Мусохранов М.В., Антонюк Ф.И., Калмыков В.В. // Наука и образование. 2014. № 11. С. 45-51.

[6] Калмыков В.В., Мусохранов М.В., Малышев Е.Н., Зенкин Н.В. // Современные тенденции развития науки и технологий. 2015. № 6-2. С. 50-52.

[7] Шебзухова И.Г., Арефьева Л.П. // Изв. РАН. Сер. физ. 2015. Т. 79. № 6. С. 896-899. [Shebzukhova I.G., Aref'eva L.P. // Bulletin of the Russian Academy of Sciences: Physics. 2015. Vol. 79. N 6. P. 811-814.]

[8] Арефьева Л.П., Шебзухова И.Г. Физико-химические аспекты изучения кластеров, наноструктур и наноматериалов / Под. ред. М. Самсонова, Н.Ю. Сдобнякова. 2015. Вып. 7. C. $52-58$.

[9] Арефьева Л.П., Шебзухова И.Г. // ФТТ. 2016. Т. 58. Вып. 7. C. 1249-1253. [Shebzukhova I.G., Aref'eva L.P. // Phys. Sol. Stat. 2016. Vol. 58. N 7. P. 1289-1294.]

[10] Пантелеев К.В., Свистун А.И., Жарин А.Л. // Приборы и методы измерений. 2014. № 2 (9). С. 107-113.

[11] Пантелеев К.В., Свистун А.И., Жарин А.Л. // Приборы и методы измерений. 2015. № 1 (10). С. 56-63.

[12] Жарин А.Л., Гусев О.К., Свистун А.И., Тявловский А.К. // Известия Тульского государственного университета. Технические науки. 2011. № 5-2. С. 286-295.

[13] Тявловский А.К., Жарин А.Л., Гусев О.К., Воробей Р.И., Мухуров Н.И., Шаронов Г.В., Пантелеев К.В. // Приборы и методы измерений. 2017. Т. 8. № 1. С. 61-72.

[14] Свойства элементов: справочник / Под ред. М.Е. Дрица. М.: Металлургия, 1985. 672 с.

[15] Шебзухова И.Г., Арефьева Л.П., Хоконов Х.Б. // ФТТ. 2009. T. 51. № 12. C. 2400-2403. [Shebzukhova I.G., Aref'eva L.P., Khokonov K.B. // Phys. Sol. Stat. 2009. Vol. 51. N 12. P. 2553-2556.]

[16] Алчагиров Б.Б., Альбердиева Д.Х., Горчханов В.Г., Дадашев P.X., Элимханов Д.З. // Вестник АН Чеченской республики. 2015. № 4 (29). С. 8-21. 